\title{
coloquios de directores y técnicos de fábricas de cemento
}

En el número gg de la Revista \&Informes de la Construcción», editada por el Instituto Técnico de la Construccí́n $y$ del Cemento, aparece, bajo el título genérieo de Aotividades del Instituto, un editorial dedieado a glosar el desarrollo de estos Coloquios, recientemente celebrados en Costillares.

No se trata de repetir aquí to que ya quedó expuesto en el artículo de la citada Revista, el cual fué coneebido con un earácter informativo general.

El tema principal de este primer artículo sobre los II Coloquios de Directores y Técnicos de Fábricas de Cemento, contiene las alocuciones pronunciadas en los actos de apertura y clausura de los mísmos, a cargo de las personalidades que los presidieron y tomaron parte activa en ellos.

Comenzaron los actos el día 11 de marzo con la recepción de los asistentes, a cargo del
Excmo. Sr. D. Federico Turell Boladeres, Presidente del Instituto Técnico de la Construcción $y$ del Cemento, quien dirigió a los presentes la siguiente alocución:

"Como Presidente deI Consejo Técnico Administrativo de este Instituto, asumo el honor que para mí supone el dedicar a ustedes unas palabras de bienvenida $y$ de salutación, así como de satisfacción y de agradecimiento por

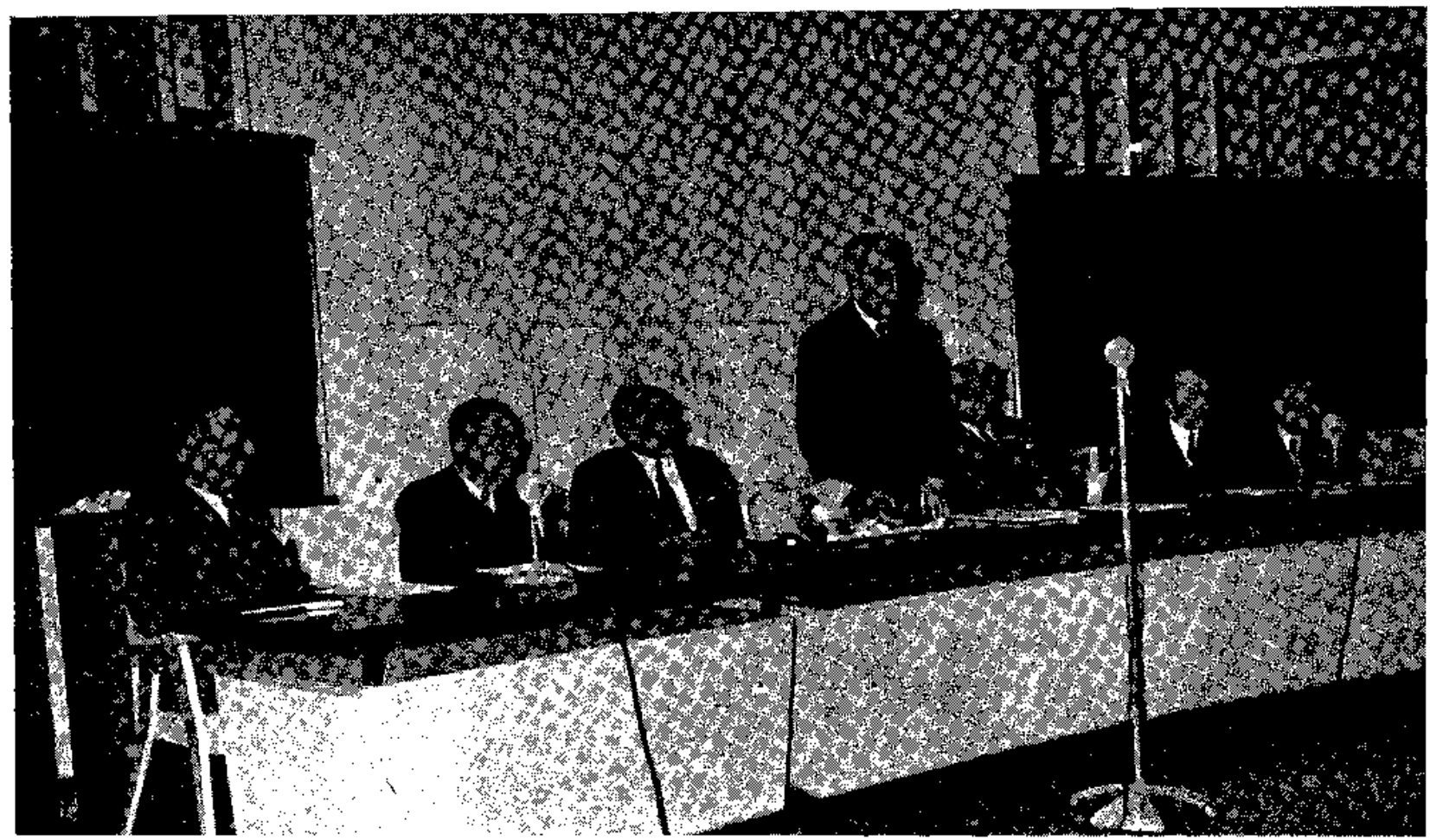


su asistencia a estos Coloquios, de cuyos resultados no es dificil augurar gran provecho a los fines que los motivan, pues basta comprobar la naturaleza e importancia de Ios temas que en ellos_se van a plantear y la destacada valia de todos y cada uno de los que aqui están, especialmente de los que tan amablemente se han ofrecido a desarrollarios a modo de ponencias, por lo que desde ahora les anticipo nuestra gratitud.

Además, abona la seguridad del éxito que prevemos, el desarrollo y los resultados que se obtuvieron de los primeros. Coloquios análogos, que celebramos en 1954 y que han justificado sobradamente nuestro deseo de proseguirlos $\mathrm{y}$, en lo posible, mejorarlos.

Creo interpretar el sentir de todos, dedicando en estos momentos un expresivo recuerdo a nuestro Director, D. Eduardo Torroja, cuya ausencia, si bien lamentamos por vernos privados de sus profundos conocimientos y larga experiencia sobre la materia de que vamos a tratar, nos satisface, en cambio, como españoles, saber que su forzado alejamiento en estos días obedece a su reconocido prestigio internacional, que ha dado lugar a ser llamado por algunos Centros y Universidades de los Estados Unidos de América del Norte, para determinadas labores de carácter científlco, aigunas de ellas relaclonadas precisamente con las actividades de este Iŕstituto. Sirvan, pues, estas manifestaciones para justiflcar su ausencia, a la vez que cumplo gustoso el encargo que me dejó de saIudar a ustẹes en su nombre.

No voy ahora a ponderar y detallar la misión que el Instituto tiene encomendada por el Patronato "Juan de la Cierva", del cual depende, $\mathrm{y}$ que, como su denominación indica, se contrae exclusivamente a la investigación técnica sobre Ia construcción y sus materiales, y muy especialmente el cemento. La amplia y bien expresiva reseña que acerca de su creacfón, organización y funclonamiento contiene la Revista "Costillares es así", que todos conocerán, y especialmente el resumen que en ella se publica por nuestro muy estimado Secretario General, D. Jaime Nadal, asi como la publicación más reciente titulada "Instalaciones en Costillares", del Dr. J. Calleja, Jefe de nuestro Departamento de Física y Química, me eximen de entrar en pormenores sobre el particular.

Pero sí constdero oportuno puntualizar que la investigación técnica referida únicamente a un material de construcción, es cosa relativamente contemporánea, hasta el punto de que puede asegurarse que no existe todavía ningún Centro del tipo de este Instituto, que se encuentre ya en plena madurez de formación y con directrices perfectamente deflnidas, como ya Io están otros Centros de investigación. Conocemos, en este aspecto, la labor que realizan gran número de Instituciones análogas de muy diversos paises, dedicadas a investigacfones sobre el cemento, y limitándonos a veinticuatro de aquellas de mayor importancia y con las que mantenemos un intercambio más intenso: belgas, danesas, francesas, portuguesas, suecas, suizas, inglesas, argentinas, brasileñas, canadienses, norteamericanas, uruguayas, indias, africanas y japonesas, se observa claramente que todas ellas se hallan en periodo de evoluctón, con la característica de desarrollo ráplđo que suele ser propio de los Centros jóvenes, a la cabeza de los cuales se encuentra nuastro instituto.

Cuando en 1949 se constituyó este Instituto con su actual doble modalidad técnica, es decir, referida a la construcción y al cemento, nuestro Director, Sr. Torroja, hombre excepclonal, cuyas geniales características son tal vez más conocidas fuera que dentro de nuestra Patria, llevaba ya muchos años dedicado a estas labores de investigación técnica, $\mathrm{y}$ sin embargo, antes de organizar el actual Instituto, tal como hoy lo vemos, hubo un periodo previo de información, con la visita sistemática a los principales Centros análogos al que pretendíamos organizar y que entonces existían por Europa.

Hoy en dia, nuestro Centro es uno de los más visitados y de fama más justamente ganada, hasta el punto de que nuestro Director ha sido reclamado desde venezuela para organizar un Instituto análogo al nuestro, lo mismo que desce Ia Argentina, donde estuvo con parecido motivo hace cinco años. Es muy interesante en este aspecto el hecho de que el Sr. Torrofa ha sido llamado hace poco por la Universidad americana de Raleigh, donde se encuentra actualmente, para desarrollar un 
curso completo de iniciación en las labores de investigación, precisamente referidas a la construeción $\mathrm{y}$ al cemento.

También nos place constatar que el Instituto noruego, asi como otros hispanoamericanos, actualmente en formación, han mandado Profesores a nuestro Centro para estudiar nuestra organización $\mathrm{y}$ orientaciones.

Desde su creación, con la señalada doble misión que le encomendó el Patronato "Juan de la Cierva" en 1949, empezó a desarrollar sus trabajos, pero su labor intensa y más eflciente de investigación sólo pudo acometerla el Instituto al instalarse en este edificio propio, hace solamente unos cuatro años, ya que con anterioridad hubo de dedicarse principalmente, como era indispensable, a la formación de especialistas para dichas tareas, no corrientes ni usuales, y a la puesta a punto de las técnicas de investigación peculiares del cemento, que en su forma más moderna se habian desarrollado en otros paises, y particularmente en Suecia, Francia, Inglaterra y Estados Unidos.

Es sabido que toda investigación técnica puede tener dos aspectos o finalidades no siempre coincidentes: uno de ellos se contrae a la investigación constante, desde luego, pero reducida a los términos de inmediato Interés para una determinada factoría o de aplicaclón del producto; el otro es el de la investigación de más altos vuelos, dedicada a explorar no sólo el campo que cubren las diversas factorias de un país, sino también a poner jalones en todo el ámbito en que se prevé puede tener un desarrollo futuro, más o menos inmediato, la producción o el consumo del producto en cuestión.

La primera de dichas finalidades es cronológicamente anterior a la otra $\mathrm{y}$, en general, más conocida, habiéndola satisfecho de antiguo, en mayor o menor escala, todos los buenos fabricantes de cualquier producto, $y$ ha alcanzado un desarrollo extraordinario en determinadas industrias, como la química, la siderometalúrgica, la electrónica, etc., sin que haya sido desatendida, según sus posibilidades, por la factorías de cemento de mayor importancia. Tal flnalidad inmediata era cubierta hasta hace relativamente poco tiempo por las propias industrias y por las fábricas de maquinaria.

Pero, tan pronto como aparece la necesidad de explorar todas las posibilidades y directrices por las que pueda derivar en un futuro más o menos inmediato una industria ceterminada, surge la necesidad de agrupar y coordinar los esfuerzos de todos Ios interesados directa 0 indirectamente en el producto de que se trate, mediante la constítución de Centros donde un grupo de especialistas en número muy superior al que cualquier factoría pueda mantener por si de modo permanente, y con un completo utillaje y elementos más amplios $\mathrm{y}$ adecuados, lleve a cabo de modo primordial esas investigaciones de carácter general y extenso a que hemos aludido, sin dejar de cooperar o atender, antes bien, estimulándola y facilitándola, la práctica de la Investigación en la primera de las expresadas modalidades, es decir, en la resolución de los problemas individuales e inmediatos planteados en cada factoria, e incluso en la solución de los parciales que se presentan a veces en una determinada fase o escalón de la producción.

Es frecuente en la elaboración y obtención de un producto que, una vez conseguida una demanda suflciente y satisfactoriamente rentable, se deje olvidada la preocupación constante y necesaria para el perfeccionamiento de las técnicas de producción. Sin embargo, es obvio que este estatismo de la industria, preocupada tan sólo por los quehaceres diarios de la fabricación, es contrario al dinamismo y fluctuación de los mercados, ante Ia aparíclón de nuevos productos de fuerte competencia con los existentes. Entonces es cuando los fabricantes, alarmados por las consecuencias que la nueva situación les crea, acuden a los Centros técnicos de investigación en demanda de determinados estudios e informes, con objeto de salvar su economía amenazada.

En este aspecto, y por lo que se reflere al cemento, nuestro Instituto viene velando $\mathrm{y}$ ocupándose intensamente del estudio de las cualidades $y$ condiciones de aquel producto con relación a las nuevas técnicas de construcción en constante y muy acusada evolución. Así, por ejemplo, ya está trabajando teórica y experimentalmente en los hormigones que un día pueden ser necesarios y ade- 
cuados para la construcción en gran escala de los afirmados de carretera, lo que exigirá aglomerantes de muy especiales caracteristicas, cuya obtención habrá estudiado para poder contestar, en caso concreto y oportunamente, la consulta que a las fábricas interese. Asimismo sabe el Instituto en qué princlpios se basan las nuevas tendenctas nacionales y extranferas que hacen posible las normales construcciones de modernos tipos estructurales, que en clerto aspecto parecen atrevidos y que, desde luego, requieren extremado culdado en la obtención de los hormigones de algunas de sus partes, para que su resistencia a los esfuerzos de diversa indole, a que habrán de hallarse sometidos, hagan posible la realización de esas nuevas estructuras, todo lo cual exige a su vez determinadas y ya conocidas características del cemento, para la consecución de las cuales analiza y ensaya en sus Laboratorios y Fábrica Piloto los materiales que intervienen en la fabricación de aquél, a fin de disponer de los estudios necesarios para poder evacuar, en su día, cualquier consulta sobre el particular.

Por su constante relación, como así es de desear, con los fabricantes, tanto de piezas para construcción como de aglomerantes, dentro y fuera de España, conoce el Instituto cuán lentamente avanza la industria de prefabricación de elementos, debido en gran parte a no contar aún con un cemento de endurecimiento tan rápido que contrarrestre la competencia de otros materiales en piezas prefabricadas, lo que da lugar a que se reduzca, en no pequeña escala, el campo de aplicación de aquel prođucto. Por ello, en su deseo de solventar aquella dificultad $y$ otros inconvenientes de diversa indole, el Instituto dedica buena parte de sus tareas al estudito de escorias, productos de adición, tratamientos especiales del hormigón y del cemento, etc., ocupándose igualmente de las investigaciones que podríamos llamar básicas, como son: el mejor conocimiento de la constituctón del clínker, Ia obtención de especies puras, y otros temas de análoga importancia, tanto en el terreno puramente técnico como en el aspecto clentífico, convencidos de que de tales estudios fundamentales se derivarán aIgún día realidades prácticas de venturosa aplicación, y no queremos que España se vea al margen - quede rezagada de lo que hagan otros países, defando de aportar su posible colaboratión al progreso de la ciencia.
Estas y otras investigaciones se lievan a cabo, en general, por iniciativa de los propios Centros de su especialidad, como ocurre con nuestro Instituto, por cuanto éstos tienen, por razón de su función, una visión más general o panorámica de toda esta clase de problemas, para ahondar y resolver los cuales se van formando grupos de investigadores y de personas especializadas, poniendo a su disposición los recursos económicos y elementos necesarios para dicho fin. Sin embargo, en este Instituto se da al propio tiempo especial importancia a la investigación sobre problemas de inmediata aplicación en todo aquello que sugieren los interesados en la fabricación y empieo del cemento, y es motivo de orgullo y de satisfacción de este Centro comprobar cómo los industriales consultantes se dan cuenta de la diligencia $y$ buen deseo con que todos son atendidos, labor que en algunos casos, por la naturaleza del asunto, es solamente conocida por el propio peticionario, dada la absoluta reserva con que se llevan a cabo las investlgaciones y ensayos pertinentes solicitados, cuyos resultados se confían únicamente a aquél, como así podría conflrmarlo alguno de los que se hallan en esta sala.

Claro está que por su carácter fundacional y misión que tiene señalada, el Instituto ha de permanecer absolutamente neutral y ajeno a cuestiones o competenclas comerciales no relacionadas con la técnica exclusivamente, no sólo porque la indole de su función asi lo expresa en su propia denominación, sino porque, de faltar a ello y mediar directa o indirectamente cualquier interés económico que no sea el general del país, perderian, cuando no carecerían de la debida ecuanimidad y solvencla, los informes que en ocasiones se le plden, a veces por parte de autoridades, en relación con hundimientos $\mathbf{u}$ otros accidentes desgraciados que ocurren en las construcciones, o por Organismos oflctales, sobre la posibilidad de utilización de uno u otro aglomerante en obras de determinada clase, etc., todo lo cual requiere una plena libertad de juicio basado en experiencia técnica, y una absoluta independencia.

Gracias a permanecer flel a estas consignas, el Instituto ha podido aconsejar con elevado criterlo a todos aquellos fabricantes que en determinado momento se interesaron por los problemas de estabilidad del volumen del pro- 
ducto, con arreglo a ciertas normas; y tarnblén, aceptar el compromiso de tarar aparatos en laboratorios de fábricas, suministrar arena normalizada para ensayos de resistencia, medir los rendimientos de maquinaria instalada, aconsejar respecto a la marcha de determinados hornos, etc.; evacuar consultas cada día en mayor número, sobre diversas cuestiones, algunas acerca del establecimiento o ampliacíón de fábricas a la vista de muestras de diversas materias primas, del mismo modo que han sido reconocidas posibles canteras $\mathrm{e}$ interpretado prospecciones, de cuyos resultados a nadie se ha dado conocimiento, por nuestra parte, fuera de al propio peticlonario de la investigación.

Sirvan estas manifestaciones, expuestas con toda sinceridad y el mejor deseo, para invitar a aquellos que no han utilizado todavía los servicios del Instituto, que no vacilen en hacerlo cuando se les presente la ocasión, puesto que nuestra mișión $\mathrm{y}$ voluntad es contribuir en lo posible a orientar o resolver cualquier problema de los que les competen, sin escatimar esfuerzos y poniendo a contribución todos nuestros recursos, acudiendo incluso, st ello fuera necesario, a nuestros corresponsales extranjeros.

Finalmente, y a modo de resumen de esta clase de actividades del Instituto relacionadas con el cemento, os diré que hasta la fecha, y sólo én los años 1955 y 1956, hemos recibido 545 consultas, de las cuales 98 provienen de fabricantes de cemento y se refieren a temas de fabricación, 85 se refieren al cemento como constituyente de morteros y hormigones y el resto a temas varlos de construcción también relacionados con el cemento en su mayoria, para actuales y futuros fabricantes de este producto.

Perdonadme que haya abusado de vuestra benévola atención, y paso a invitar a mi querido compañero del Consejo, D. Julián Rezola, a que nos ilustre especlalmente sobre las orientaciones previstas para el desarrollo de estos II Coloquios, que desde ahora declaro abiertos."

Acto seguido tomó la palabra el ilustrísimo señor don Julíńn Rezola Zabaleta, Vocal del Consejo Técnico Administrativo del Instituto, quien, al explicar a modo de introducción la finalidad y detalles acerca de los II Coloquios que en ese momento se iniciaban, se expresó en los siguientes términos:

"La celebración de los I Coloquios de Directores y Técnicos de Fábricas de Cemento, precursores de estos que comenzamos hoy, tuvo lugar, como todos sabéis, en el mes de octubre de 1954.

Ya entonces me cupo el honor de ser designado para dirigir a los asistentes de aquéllos unas palabras de salutación y bienvenida $y$, al mismo tiempo, para exponer a manera de introducción los fines que con tales coloquios se perseguían. Tal vez sea esa la razón por la que he vuelto a ser designado ahora.

El tiempo transcurrldo desde entonces, asi como la evoluctón que en el mismo ha experimentado el Instituto Técnico de la Construcción y. del Cemento, han hecho pensar en Ia conveniencia de repetir el ensayo que tan agradables y fructíferos resultados dió en aquella ocasión.

Hoy se repite, pues, la historia, y, puesto que todos o la mayoria de los que hoy nos encontramos reunidos ya lo estuvieron tamblén entonces, no es preciso detenerse a exponer cuáles fueron estos resultados, presentes en el ánimo de todos y patentes en las publicaciones a que dferon Iugar las ponencias entonces presentadas, así como las interesantes discusiones y dí́logos que las mismas suscitaron.

Aquellos I Coloqulos, tal vez por primeros, nos permitieron apreciar algunas deflciencias en su desarrollo, $y$, en el tiempo intermedio, ha habido ocasión de pensar en subsanarlas, dando a los Coloquios presentes un giro algo distinto en cuanto a su desenvolvimiento.

Nos han servido para tal objeto varias e Interesantes sugerenclas recibldas, a cuyo propósito voy a hacer unas breves indicaciones.

La palabra coloquio encierra en sí el sentido de díálogo o diálogos entre varias personas interesadas en un mismo tema. No hay, pues, coloquio sin conversación. $Y$ a fin de que ésta pueda tener lugar, es preciso que en el 


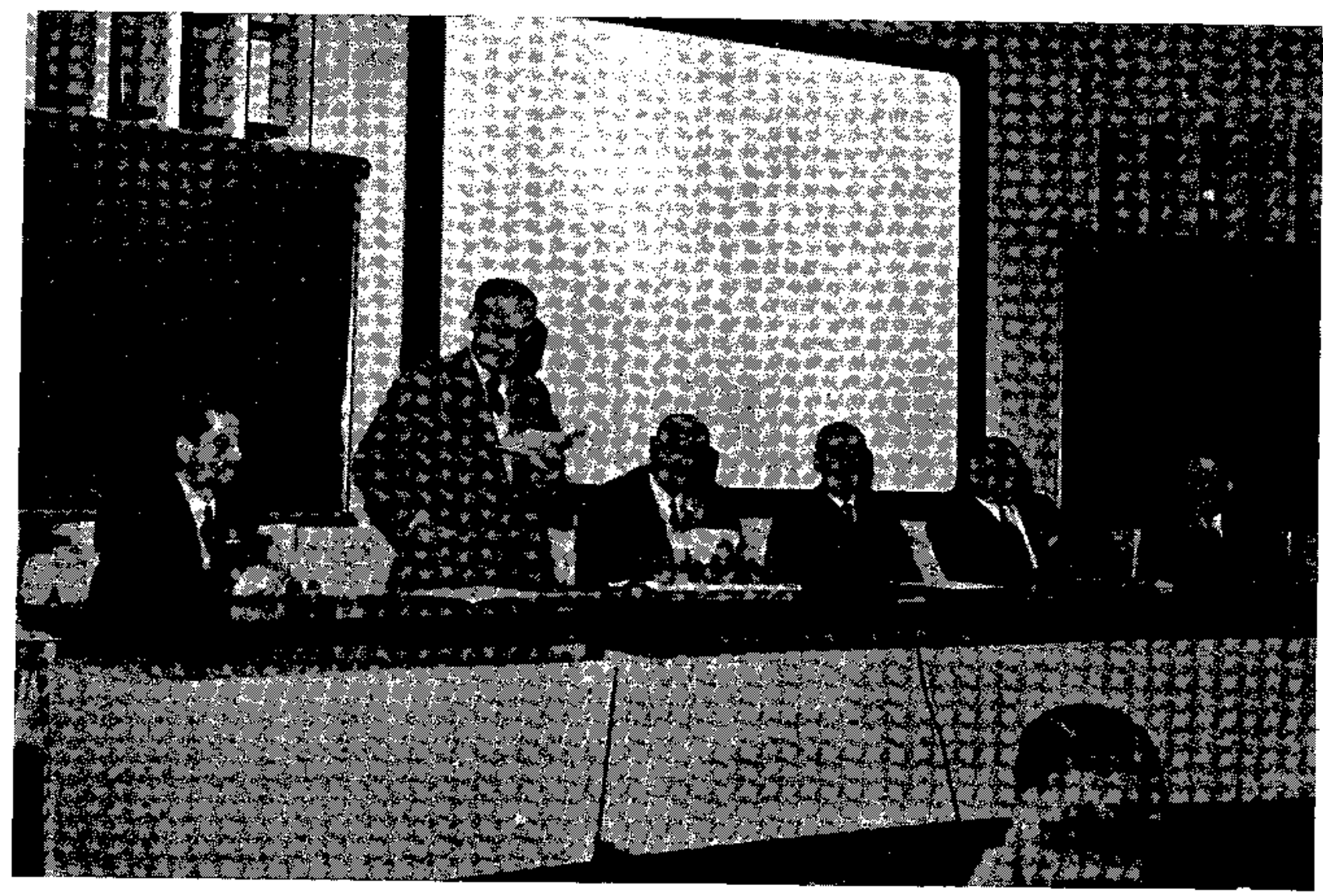

tiempo fljado-limitado, naturalmente-para cada exposición, puedan todos los oyentes que lo deseen hacer preguntas, aclaraciones u observaciones.

Con tal objeto, se ha dispuesto el reparto de los temas a presentar, entre dos Comisiones de trabajo, que han de actuar simultáneamente. Se ha procurado, dentro de lo posible, agrupar en cada Comisión los temas que más afinidad presentan entre sí.

Otra de Ias razones que han inducido a tal resolución, es la del escaso tiempo que los múltiples quehaceres de cada uno de los asistentes permite dedicar a estas tareas, en vista de la imposibilidad de una ausencia prolongada de sus ocupaciones habituales. Otra más, el éxito que tal dispositivo de trabajo ha tenido en la celebración de reuniones de análogas características.
Por ello, el desarrollo de estos Coloquios tendrá lugar, simultáneamente, en dos salas, en las que actuarán los distintos ponentes, asistidos, en cada una, por dos secretarios que forman parte del personal técnico del Instituto.

Sin embargo, hay que reconocer que no ha sido fácll el acoplamiento de los temas en tales condiciones, ni es perfecto el definitivamente adoptado.

Es indudable que todo ello dará lugar a nuevas sugerencias, que de antemano agradecemos, y que serán motivo de nuevos perfeccionamientos en reuniones futuras.

Una vez centrada así la atención de los asistentes en las ponencias que más sean de su interés, voy a hacer un ruego a los actuantes. $Y$ es el de que procuren dar a su exposi- 
ción una duración prudencial, con objeto de dejar margen a esos diálogos y conversaciones a que antes aludía, y que son el alma y la esencia de los verdaderos Coloquios.

Pensad que los đetalles de exposición quedarán conveniente e íntegramente plasmados en la publicación definitiva que de los temas expuestos hará después el Instituto.

$Y$ pasando ahora a hablaros de la evoluctón que ha experimentado el Instituto Técnico de la Construcción y del Cemento, a que antes aludia, puedo dectros, y vosotros lo comprobaréls, que sus instalactones están virtualmente terminadas. $\mathbf{Y}$ digo virtualmente, porque nunca una obra es completa, si ha de ser perfecta $O$ casi perfecta.

En el folleto que todos habéls reclbido, tenéis una breve exposición de las nuevas tnstalaciones, asi como de las ampliaciones de las ya existentes, particularmente por lo que se reflere a Laboratorios de Análtsís y Ensayos, Planta Plloto para la fabricación de cemento y equipos auxiliares, que sirven satisfactorlamente de puente de unión entre los estudios y experiencias realizados en el Laboratorio y los a realizar a escala semi-industrial e industrial.

$\mathrm{Y}$ este punto de unjón, este enlace entre vosotros y el Instituto, es el que debemos de buscar en estos Coloquios, en estas reunlones periódicas, en estos cambios de impresiones.

Existen en estos momentos en el mundo problemas de tipo general para la industria, que en España tienen una muy grande repercusión, y que en el caso de los combustibles, por ejemplo, se hacen agobiantes para las fábricas de cemento. Problemas que los técnicos cementeros pueden afrontar, en intima colaboración con el Instituto. Asi, la posíbllidad del empleo de determinados carbones, en combustión mixta con el fuel-oil.

El estudio conjunto de este tipo de problemas, la aportación de datos de experimentaclón, de soluciones y de conclusiones, aparte de servir de fuente valiosa de información en estos momentos, habrá de destacar el carácter práctico del Instituto para los fabricantes, y sobre todo, el amplio campo que una acción así enfocada puede significar para la economía nacional.

Nunca os insistiré bastante sobre las consecuencias prácticas que una tal colaboración entre los técricos de las fábricas y los del Instituto proporcionará a todos, y por estimar que esa labor es definitiva, es por lo que la destaco en estas breves palabras, que sirven de apertura a los coloqulos:

$\mathbf{Y}$, precisamente por estar todos reunidos en estos días, es de estas conversaciones, de estos cambios de impresiones, de donde pueden sallr los cimientos de esa colaboración, para que obtenga sus mejores frutos. El Consejo del Instituto ha de recoger vuestras impresiones en este sentido $\mathrm{y}$ ha de saber encauzarlas, y yo, en nombre del mismo, os invito a que uno de los temas de esas conversaclones entre vosotros, sea precisamente ése, para que de las mismas surjan vuestras propuestas, base para la colaboración.

Como sabéis, el Instituto está y estará siempre a vuestra disposición, siendo nuestro mejor deseo $\mathrm{y}$ nuestro anhelo el poder dar en todo momento cumplida satisfacctón y resolución a los problemas que podáis plantear, y que trataremos por todos los medtos de resolver, dentro de ese espíritu de camaradería y colaboración que se os brinda."

Después de las sesiones de trabajo desarrolladas por las dos Comisiones creadas al efecto, y constituída cada una por su grupo de ponentes y dos Secretarlos del I. T. C. C., estos últimos informaron en sesión plenarla acerca de los trabajos presentados, exponiendo las conclusiones provislonales para su aprobación, en su caso, como definitivas.

El Presidente, Sr. Turell, concedió la palabra en primer lugar a D. José Calleja Carrete, Secretario de Organización de los Coloquios, el cual se expresó así:

"Excelentisimos señores, señores:

Como Secretario de estos Coloquios que han venido celebrándose, y antes de que los Se- 
cretarios de sala informen acerca de los actos desarrollados en las suyas respectivas, quiero destacar, de una manera general, varios hechos que todos habrán podido observar:

Primero, que el programa se ha cumplido en la forma anunciada, salvo las modifleaciones motivadas por el luctuoso suceso de todos conocido.

En segundo lugar, que, de una manera absoluta, todas las ponencias presentadás han ocupado un tíempo mayor del previsto. La causa no ha sido otra que el gran número de intervenciones que han tenido lugar al final de cada tema presentado, $y$ el vivo interés de estas mismas intervenciones, reflejo a su vez del interés de las ponencias en sí.

En el informe de los Secretarios de sala, no se hará una mención, ni particular ni detallada, de cada una de estas intervenciones, pues ello llevaría excesivo tiempo. Por ello, mis compañeros informarán de un modo breve, destacando tan sólo aquellos aspectos más salientes en cuanto a interés general.

Haré, a continuación de su informe, el de las sesiones plenarias, así como algunos ruegos."

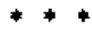

A continuación, D. Manuel del Campo GaIarza, Secretario de una de las Comisiones de trabajo, dió cuenta en su nombre, y en el del también Secretario de la misma, D. Francisco Soria Santamaría, de los trabajos realizados por su Comisión, leyendo el siguiente informe:

"La primera ponencia presentada en la sala A, estuvo a cargo de D. Julián Rezola Izaguirre, de Cementos Rezola, S. A., en la que trató del interesante tema "Hornos verticales".

Versó fundamentalmente de su experiencia en este tipo de hornos, de la que se deduce el interés que presentan como solución práctica y adecuada para pequeñas producciones.

Expuso a continuación las caracteristicas y condiciones óptimas que-según su experienm cia-deben reunir los combustibles, materias primas, dosiflcación y mezcla de las mismas, así como de la marcha general de fabricación.

A continuación, y abierta la discusión, intervino en ella un numeroso grupo de especialistas, que expusieron sus puntos de vista sobre los distintos aspectos técnlcos de esta modalidad.

La segunda ponencla, "Refractarios para hornos rotativos de cemento", estuvo a cargo de D. José Maria Balaguer de Pallejá, de la Companía General de Asfaltos y Portland Asland.

Sistematizó en ella una serie de estudios realizados por él sobre las caracteristicas fisicoquímicas de este tipo de materiales, y se lamentó de la no existencia de un Plíego de Condiciones que permita conocer al usuario las características mínimas exigibies a los mismos.

De la discusión de esta ponencia se dedujo la conveniencia de que el I. T. C. C. colabore, en su día, en la posible preparación de un Pliego de Recepción de este tipo de materiales.

Se dieron diversas opiniones sobre problemas tan interesantes como formación de costra, anillos, deformación mecánica del horno en su repercusión sobre el refractario, experiencia del comportamiento de diversos tipos de refractario, solicitándose de $\mathrm{Mr}$. Folliot, que nos honraba con su asistencia, expusiera brevemente la experiencia de su país en tema tan interesante.

La tercera ponencia presentada en esta sala estuvo a cargo de D. Darío López Peciña, de la Compañía General de Asfaltos y Portland Asland, y se tituló "Los combustibles y la combustión en los hornos de cemento".

Después de exponer el orador una serie de estudios teóricos sobre el problema de la combustión en hornos de cemento, se planteó el problema de la utllización de carbones de baja calidad, con el fin de sacarles el máximo rendimiento.

'Tras una discusión movida del tema, se puso de manifiesto por parte de los asistentes el 


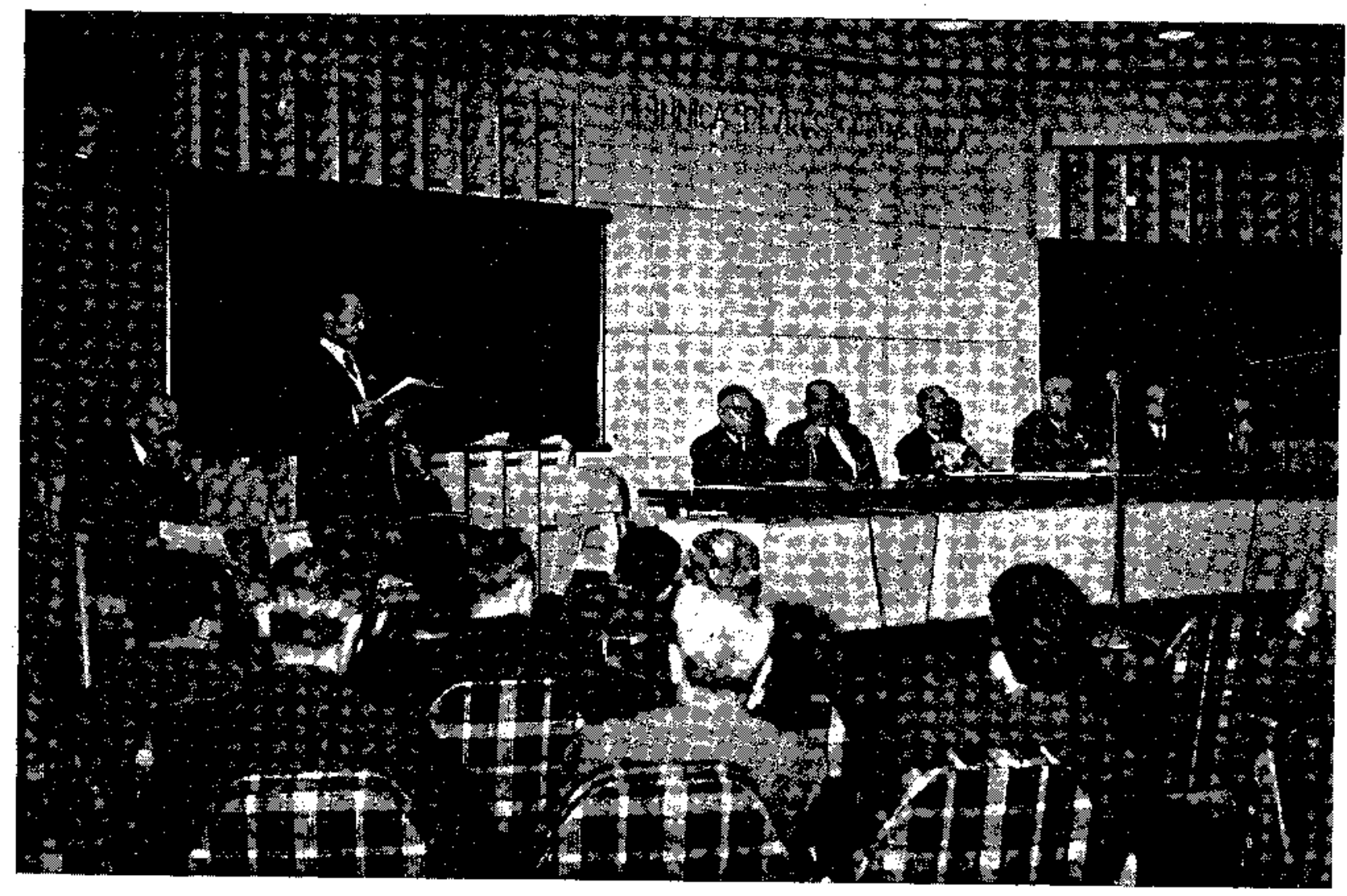

interés del mismo, pero dentro de ciertas limitaciones compatibles con la calidad del producto que se desea obtener.

Como consecuencia de esta ponencia, varios asistentes han manifestado el deseo de que se trate de adoptar métodos de ensayos, comunes a suministradores y usuarios de carbón, con el fin de unificar resultados de calldad.

La cuarta ponencia, "Combustión conjunta de fuel-oil y carbón", estuvo a cargo de don Altredo Serratosa Nadal, de la Compañía Valenciana de. Cementos Portland.

Expuso en ella su experiencia de dos años de funcionamiento con la combustión mixta Indicada, señalando las causas que le exigieron tal instalación, dadas las caracteristicas especiales de su fabricación: el cemento blanco.
Después de describir las caracteristicas de la Instalación, resumió las condiclones de marcha de funcionamiento.

En ésta, como en las otras ponencias, el intercambio de impresiones entre los que utilizan este tipo de instalación fué amplio.

"La fabricación de cementos portland siderúrgicos" constituyó la quinta ponencla presentada en la sala $A, y$ estuvo a cargo de D. Juan José Uría López, de Industrias del Cemento, S. A.

Expuso el ponente una serie de estudios por él realizados sobre este tipo de cementos, destacando de un modo especial las condiciones de molienda y mezclado de sus componentes, tanto en conjunto como por separado. En unos amplios cuadros resumió los resultados experimentales por él obtenidos. Abierta la 
discusión, se propuso por uno de los asistentes la posible redacción de una norma que recoja la posibilidad de aceptar la fabricación de un cemento portland con la adición de un $10 \%$ de escoria.

La sexta ponencia estuvo a cargo de D. Alberto Virella Bloda, de Ia Companhia Portuguesa de Cimentos Brancos, que versó sobre "Los ensayos de calidad en los laboratorios de fábrica".

Expuso el conferenciante, de un modo amplio, la adopción por las fábricas portuguesas del método RILEM para ensayo de sus productos y, a tal respecto, pasó revista a los métodos físicos y químicos, señalando la conveniencia de que los fabricantes estudien detenidamente cuantas propuestas surgen en tal sentido, con el fin de adoptar las medidas necesarlas en Ia fabricación para que los productos obtenidos cumplan cuantas exigencias se les impongan. La ponencia fué ampliamente discutida.

"El problema de la mano de obra en las fábricas de cemento. Mecanizactón", fué la ponencia presentada por D. Patricio Palomar Llovet, de la Compañía General de Asfaltos y Portland Asland.

Versó en ella sobre la importancia actual del capitulo de personal en el precio de coste; productividad de las fábricas de cementos españolas $\mathrm{y}$ norteamericanas; nivel de productridad posible a alcanzar en las fábricas españolas, así como de la forma de mejorar dicha productividad en las distintas secciones de fábricas.

Ina discusión del tema llevó a solicitar del ponente amplios datos de la industria americana, y por los asistentes se vló la conveniencia de racionalizar dichos métodos, de acuerdo con las características de las fábricas espanolas.

Por último, D. Carlos Gascuñana, de la, Compañia General de Asfaltos y Portland Asland, desarrolló la última ponencia, titulada "Grandes voladuras".

Expuso en ella los últimos adelantos en este típo de trabajos, con el fin de consegujr gran- des rendimientos en la explotación de canteras.

Esta, como las anteriores ponencias, fué ampliamente discutida $y$ el conferenciante informó detalladamente a los asistentes sobre cuantos extremos fueron tratados."

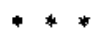

Acto seguido informó D. Pablo García de Paredes, Secretario, junto con D. José Calleja Carrete, de la otra Comisión de trabajo. Su informe constaba así:

"De las ponencias presentadas en la sala $B$, la primera de ellas tuvo lugar el día 12, estando a cargo de D. José María García Gil, que habló de "Química de cementos especiales".

El ponente hizo una detallada exposición, en el aspecto químico, de los cementos puzolánicos, de escorias, aluminosos y blancos.

Reflriéndose a los cementos puzolánicos, pasó revista al origen y propiedades de las puzolanas naturales $\mathrm{y}$ artiflciales, a la actividad de las mismas y a su empleo en la fabricación de Ios llamados cementos portland puzolánicos, añadiendo una amplia menclón de las caracteristicas, ventajas e inconvenientes de las cenizas volantes, consideradas como material puzolánico.

De los cementos de escorias mencionó y describió el portland siderúrgico y el portiand de alto horno, contenidos en el Pliego español de 1930.

Al tratar del aspecto químico de las escorias destacó la influencia del proceso de granulación.

Describió las materias primas empleadas en la fabricación de los cementos alumínosos, detallando la constitución del aglomerante obtenido.

Expuso los aspectos químicos más destacados en los procesos de hidratación, fraguado y endurecimiento, así como el comportamiento de los cementos aluminosos frente a los agentes agresivos. 
Mencionó las mezclas de cementos portland $y$ aluminosos $y$, aunque los considera como portland, describió los cementos blancos, comentando la acción de algunos fundentes y mineralizadores empleados en su fabricación.

En el cambio de impresiones que siguió a esta ponencia, se pidió al I. T. C. C. que iniciase el estudio de las aplicaciones que el cemento aluminoso tiene como recubrimiento refractario.

"Dispositivos para calcular notas de deftnición del portland, de su clínker y del crudo empleado en su fabricación", por D. Antonio Sarabia González, fué la segunda ponencia, y tuvo lugar el mismo día 12.

Según el conferenclante, el Director de una fábrica, aparte de sus relaciones humanas con cada una de las personas que con él colaboran. encuentra como principales metas de su actividad:

a) Conseguir la más alta producción, al coste mínimo, a partir de los elementos humanos y tecnológtcos a su disposición.

b) Obtener productos de mercado cuya calidad sea permanentemente alta.

Esto Ultimo supone la existencia de servicios de control de producción que le han de permitir inferir, "a priori", las caracteristicas flnales de lo que está fabricando $y$, a partir de ellas, introducir, sobre la marcha, las modiflcaciones pertinentes.

Hizo notar el Sr. Sarabia que el control de la fabricación de cemento recibe la informaclón necesaria a través de la medición directa de parámetros tales como: denstdad del clínker, calcimetria del crudo, velocidad de fraguado, y por la comprobación del valor de otros, ofrecidos por el análisis químico, a saber: módulos de hidraulicidad, silícico, etc.

La necesidad de actuar rápidamente en las operaciones de control, y otras veces de establecer grandes serles de datos numéricos (por ejemplo, en el estudio estadístico de la influencia que la variación de un parámetro pueda tener sobre alguna propiedad del cemento), supone para la persona interesada en

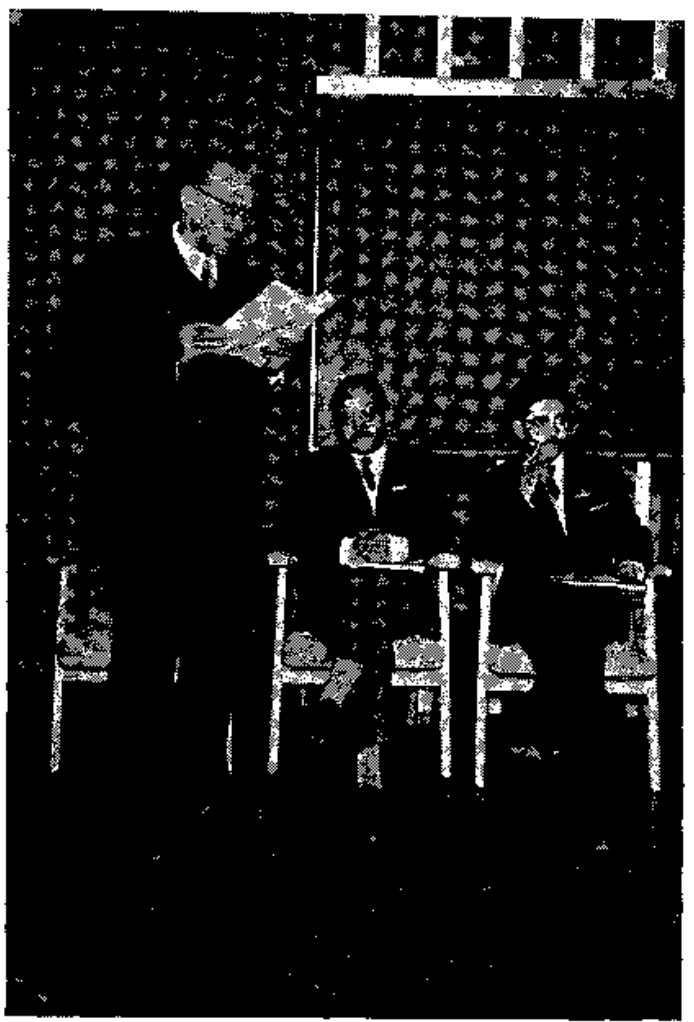

obtener tales datos, la conveniencia de conseguirlos con un mínimo de esfuerzo y de tiempo. Por ello han aparecido:

$$
\begin{aligned}
& \text { Los cuadros de valores. } \\
& \text { Las gráflcas. } \\
& \text { Los ábacos. } \\
& \text { Las reglas de cálculo. }
\end{aligned}
$$

Estas consideraclones movieron al Sr. Sarabia a idear el modelo de regla de cálculo que ofrece a la consideración de los colegas reunidos en estos coloquios. Con ella demostró cómo seguirse, de modo rápido y sencillo, la lectura del contenido de los minerales "potenclalmente" presentes, a partir del análisis químico, asi como el grado de saturación en cal, etc.

Hizo notar que la aproximación obtenlda no resta utilidad al empleo de los conceptos a que se refieren los datos empleados.

EI ponente aludió a la falta que se nota de un concepto que, una vez dominado en expresión numérica, informase del estado "actual" de la composición mineralóglca del clínker. 
Prevé para el futuro otros dispositivos que ofrezcan comodidad y rapidez en la determinación de los valores particulares de nuevos parámetros, quizás de uno solo. Su fijaclón la espera de los generosos trabajos de tantos y tan excelentes investigadores como dedican su actividad a Ia Químíca de los sólídos y al conocimiento profundo de su estructura reticular.

Los concurrentes a esta sesión de los Coloquios expresaron su vivo deseo de poder, en plazo breve, disponer del aparato ideado por el Sr. Sarabia.

Este deseo está en vías de realización inmediata por el Instituto Técnico de Ia Construcción $\mathrm{y}$ del Cemento.

La tercera ponencia fué desarrollada por D. José Laffarga Osteret, que disertó sobre "Reología de las pastas crudas".

Previa una breve reseña histórica de los principios de la Reología, desarrolló algunas consideraciones sobre el empirismo actual de los conceptos de fluidez y "manejabilidad" de las pastas crudas para la fabricación de cemento por vía húmeda, pasando a tratar de la necesidad de conseguir pastas de bajo contenido en agua para lograr mayores rendimientos calóricos y económicos en la fabricación. Se justiftca así la necesidad del estudio reológico de las pastas para conseguir una mayor eficiencia en las instalaciones de transporte.

Estudió lígeramente la teoría general reológtca, sus principios fundamentales y algunas ecuaciones de estado, definiendo algunos coeficientes reológicos principales.

Indicó la influencia de los componentes de las pastas en su conducta reológica y dió los valores de la viscosidad plástica y de la presión mínima de flujo encontrados para algunas pastas, utilizando el viscosímetro de ejes coaxiales construido y utilizado por el autor.

Finalmente dió a conocer fórmulas de aplicación práctica para calcular el gasto y las características de las bombas y tuberias.
Expuso, por último, las posibilidades que tlene el estudio reológlco de las pastas con aplicación práctica inmediata, reconocimiento de la posible tixotropia, utilización de fluidifcantes, elección del sistema de transporte, e incluso la determinación del sistema de fabricación, seco o húmedo.

Solicitó el ponente la continuación, por el Instituto Técnico de la Construcción y del Cemento, de estos interesantes estudios.

Por Ulttimo, D. Domingo Guinea Guerrero habló de "Métodos, procedimientos de ensayo y Pliego de Condiciones".

Recogiendo la experiencia adquirida por el Laboratorio de Ingenleros del Ejército durante sesenta años de trabajo, expuso su opinión acerca de los métodos de ensayo utilizados hoy en España para califlcar al cemento portland. También revisó con acertada crítica, algunos otros normalizados en otras naciones, que, por creerlos interesantes, se han empleado repetidas veces en aquel Centro.

En esta interesante y documentada critica, pasó revista a todas las pruebas físicas, fisicoquímicas $\mathrm{y}$ químicas que hoy se efectuan, tales como: agua de amasado, dosificación del mortero normal, resistencias mecánicas, limitación del yeso en el cemento, estabilidad de volumen, finura de molido, análisis químico, etcétera.

De aquellas que por más interesantes, o por disponer de tiempo y medios, ha podido estudiar, ofreció ideas concretas, verdaderas conclusiones, que fueron objeto del siguiente coloquio. De otros ensayos, sólo planteó en forma clarísima los problemas que existen a su juicio, con ánimo, dijo, de que los organismos correspondientes, o las personas más apropladas, traten, si reconocen la existencia de tales problemas, de encontrar la soluclón.

El extenso e Interesante coloquio que siguió a la conferencia reafirmó más, si cabe, la aspiración de todos por una pronta reforma del actual Pliego." 


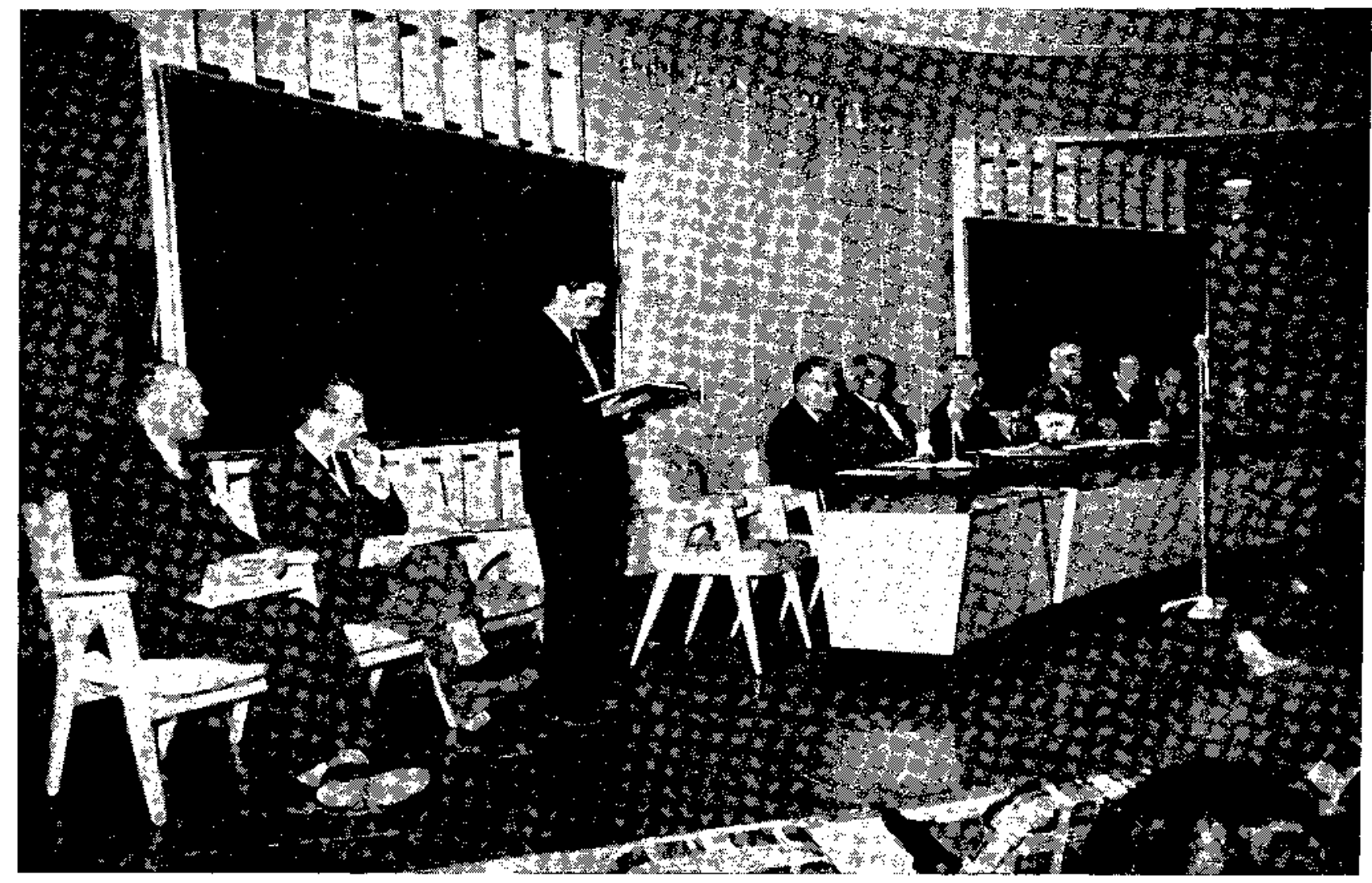

Por último, D. José Calleja Carrete, Secretario de Organización y de una de las Com1siones de trabajo, informó así acerca de las sesiones plenartas celebradas, pasando a continuaclón a hacer los ruegos que se mencionan:

"Las sesiones plenarias, por orden de su celebración, han sido las siguientes:

Dl día 11, la que corrió a cargo de $D$. José María de Arteaga, quien, con su elocuencia y amenidad bien conocidas en esta casa, nos presentó el panorama reciente de la industria del cemento norteamericana, en todos sus pormenores.

El día 12, la de Mr. Albert Folliot, Director de la fábrica de Limay, de la Societé Anonyme des Cimerits de Lafarge et du Teil, sobre "Transmisión del calor en los hornos rotato- ríos de cemento". Acerca de la profundidad y documentación de su conferencia, ustedes mismos han juzgado ya. Destaca en ella la variedad de artiflcios utilizados, a fin de poder reunir los datos numéricos necesarios que después le han permitido llegar a sus tan interesantes como, a primera vista, inesperadas conclusiones.

El día 13, Herr Dr. Hans Ihlefeldt, de la Portland-Zementwerke, de Heidelberg, trató de la "Eliminación y recuperaclón del polvo en los hornos rotatorios de cemento". De una manera muy gráfica, presentó los resultados de la investigación llevada a cabo por la Agrupación Alemana de Fábricas de Cemento acerca del origen, medición y eliminación del polvo. Conseguida la solución del probiema de Ia medida, mediante aparatos ideados y realizados en su laboratorio, ha podido estudiar la eftcacia de los distintos sistemas de elimi- 
nación, aplicados a los diferentes tipos de hornos, facilitando asi a las casas constructoras de estos equipos datos para el cálculo y comprobación de sus instalaciones. Destacó el conferenciante que la Asociación Alemana de Fábricas de Cemento propugna por que no se fle el límite para el contenido de polvo de los hurnos de las mismas.

$\mathbf{Y}$, terminados los informes sobre las ponencias, paso a hacer los ruegos a que antes me referia.

Primero, el de que disculpen cuantas deflclencias hayan podido observar en la organización de estos Coloquios.

$Y$ segundo, que nos las den a conocer, sean muchas o pocas, grandes o pequeñas, para tomar buena nota de ellas y subsanarlas en el futuro, como ya anuncló nuestro Presidente en sus palabras de bienvenida.

He de decir también que, durante el tiempo que sea necesario, la Secretaría de estos II Coloquias ha de seguir funclonando como tal, a fin de resolver, a la mayor brevedad, alguna posible cuestión pendiente. Así como para acoger y cumplimentar, con el mayor interés, todas las sugerencias que aquí se han hecho, tal como en varias ocasiones les ha manifestado nuestro Consejero D. Juiián Rezola.

Finalmente, como Secretario de los Coloquios, doy a todos los gracias: a las autoridades, por honrarnos con su asistencia; al Consejo Técnico del Instituto, por su apoyo; a mis compañeros, por su valiosa colaboración y ayuda, y, sobre todo, a los ponentes y a todos los asistentes, cuya presencia en estos días ha alegrado Costillares."

Concluída la información técnica y la expostción de conclusiones provisionales, que fueron unánimemente aprobadas como definitivas, tomó la palabra el Excmo. Sr. D. Federico Turell Boladeres, Presidente del Instituto, para dar por clausurados los II Coloquios de Directores y Técnicos de Fábricas de Cemento, expresándose en los siguientes términos:
"Creo poder tener una gran satisfacción pues el éxlto que preveia lo he logrado. El Consejo no puede menos de felícitarse. Ante estos resultados, no han de desistir ustedes de preparar nuevos Coloquios, para los cuales se invita a cada uno de ustedes para que vaya sugiriendo temas. El deseo nuestro es que todos pongan su colaboración, que será muy agradecida por parte del Consejo. Hemos de agradecer tamblén al Patronato "Juan de la Clerva" las facilidades que otorga al Instituto. Creo que todos podemos sentirnos satisfechos de todos $y$, particularmente, de los buenos resultados del cemento, uno de los temas más primordiales que aborda el Instituto.

Hemos de dar las gracias, sobre todo, a los señores Nadal y Echegaray; a los Secretarios de sala, seńores García de Paredes, Calleja, Soria y Del Campo, así como a todos sus colaboradores, pues todos han puesto en su cometido su alma y su buen deseo, cosa que el Consejo ha de tener muy en cuenta. Igualmente, a todos los Consejeros y, en particular, a los señores Rezola, Palomar y Lumbier. A todos os doy las gracias y espero que en la próxima reunión podamos sentirnos tan satisfechos como ahora.

Sugtero enviar un telegrama de salutación al Sr. Torroja, que se encuentra en los Estados Unidos, en misión honrosa para el Instituto, expresándole nuestra simpatía y buen recuerdo."

$$
* * *
$$

Acto seguido, el Presidente, Sr. Turell, procedió a la entrega de los premios del III Concurso de Temas Libres sobre Cemento, convocado por el Instituto para galardonar los mejores trabajos publicados sobre la especialidad en el triento 1953-55. El fallo corrtó a cargo de un Jurado Callficador, y recayó el premio de Fabricación en los señores D. Patricio Palomar Llovet y D. Darío López Peciña, ambos de la Compañía General de Asfaltos y Portland Asland, por su trabajo en colaboración titulado "Las operaciones de molienda en las fábricas de cemento", El premio de Investigación corresponđió a los señores D. José Calleja Carrete, Jefe del Departamento de Física y Química del Instituto Técnico de la Construcción y del Cemento, por su trabajo titulado 


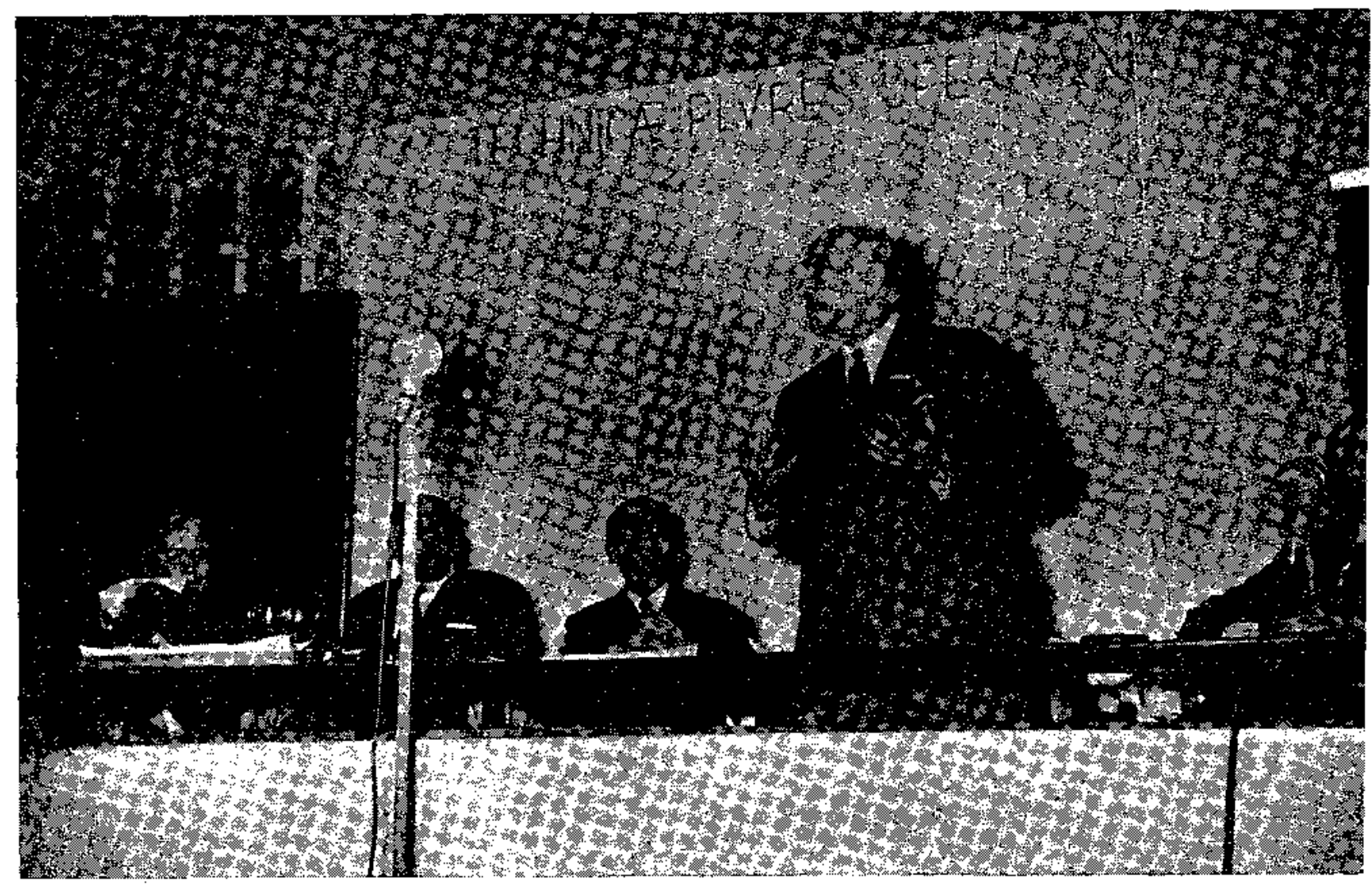

"Estudios sobre Ia constitución del clínker de cemento portland", y a D. Jósé María Tobio Sillero, Jefe de la Sección de Estudios Físicos de dicho Instituto, por su trabajo "Dos aparatos sencillos para el estudio del faguado".

$$
* * *
$$

Finalmente, el Exemo. Sr. D. José Vierna Belando, Delegado del Gobierno en la Industria del Cemento, que ocupaba la mesa presidencial, tomó la palabra y pronunció la siguiente alocución:

"Les doy a ustedes mi palabra de que no he preparado nada, ni he pensado absolutamente nada, o sea que va a hablar la sinceridad. Voy a hacer mi presentación: soy el Delegado del Gobierno en la Industrta del Cemento $y$, como tal, el pariente político que ha entrado en Ia familia cementera; soy el novio que acaba de contraer relaciones con un aglome- rante, el cemento, y ha entrado en su familia, pero sí he de decir que he entrado por la puerta grande. Llevo exactamente nueve dias en esta nueva situación. Hace algunos, he pasado el "primer fraguado"; ahora estoy en plena curva del proceso y temo que éste vaya siendo demasiado rápido, porque noto que me estoy metiendo de lleno en el tema, pues no sueño más que con él.

Si a eso añaden ustedes la simpatía desbordante de todos los componentes de esa familia que se han acercado a mí en estos días, comprenderán que estoy verdaderamente conmovido. De D. Patricio, mi profesor, y digo mit profesor porque lo primero que hice al entrar en contacto con el cemento fué preguntar por un Ilbro que del cemento tratase: me dieron el suyo; de D. Julián, con su afecto y su cariño; de D. Marcelo; del Presidente del Instituto, D. Federico Turell; del Secretarlo, Sr. Nadal; del Sr. Carpi, que estuvo a mis órdenes 
en Antlaeronáutica, y de tantos y tantos otros, no he recibido más que satisfacciones y, naturalmente, me encuentro por ello muy emocionado.

Tengo que agradecer con toda mi alma al Sr. Turell que, al invitarme, me haya dado ocasión de conocer este maravilloso centro que es el Instituto. Les aseguro a ustedes que, aun habiendo oído hablar de él, no pensé que tuviera la categoria que tiene.

¿Qué puedo hacer yo por el cemento y por este Instituto? Haré todo lo que me sea postble. Y, al prometerlo, creo llegado el momento de decir que, a más del afecto de ustedes, tengo en mi mano una gran cantidad de otros afectos entre los grandes. Sepan primero que yo estudié las primeras letras con nuestro Jefe del Estado. De su mismo pueblo y de su misma edad, jugué de niño y me preparé de joven con Su Excelencia el Generalísimo. Sepan también que uno de los que más han hecho por este Instituto, D. Juan Antonio Suanzes, es para mí como un familiar. Por otra parte, el Ministro de Industria, don Joaquín Planell, es de mi misma promoción y clase. Como ven, tengo amigos situados en la cumbre $y$, llegado el momento, no vacilaré en recurrir a ellos en apoyo de ustedes.

Les prometo que cuando me considere "fraguado" del todo, he de hablar primeramente con mi compañero Planell; he de hacerle ver Io que yo he visto. A Suanzes le diré lo mismo, tan pronto esté con él, y os prometo también que, en un plazo no muy lejano, contaré al Generalísimo todo cuanto ahora me llena de emoción.

Es decir, pretenderé por todos los međios a mi alcance colaborar, porque lo merecen; no sólo el Instituto, sino toda la familia del cemento, pues me han enseñado una cosa que yo creí que no existia: que hublese entre los técnicos el compañerismo de que han hecho gala, puesto de maniflesto al venir a contarse los "secretos" unos a otros. Es para mí una satisfacción enorme comprobar que la técnica no tiene fronteras.

Por eso les digo que, no en balde he asistido a las sesiones de apertura y clausura. He venido para establecer ese primer gran contacto que nos ha hecho buenos amigos, pues ya me considero un buen amigo de todos, y para procurar por todos los medios posibles que estos Coloquios y este Centro no queden en el silencio.

Yo prometi a mis subordinados, cuando me hice cargo de la Delegación, una sincera lealtad, una buena amistad $y$ un mutuo afecto: a todos ustedes les ofrezco y les pido un mutuo afecto. En todos los problemas que tengan, no vean en mí a un político; vean a un miembro más de la familia, que hará todo Io que pueda por simplificar y activar trámites y mejorar lo que sea susceptible de mejora.

Y nada más, señores. Muy agradecido a todos."

$$
* * *
$$

Concluídas así, virtualmente, las jornadas de trabajo que se desarrollaron con motivo de los II Coloquios, como despedida se celebró una cena en el Hotel Ritz, a cuyos postres, el excelentísılmo señor D. Patricio Palomar Collado, Vocal del Consejo 'Técnico Administrativo del Instituto, tomó la palabra para decir lo siguiente:

"Por ausencia del Director del Instituto, D. Eduardo Torroja, que es a quien correspondía hacerlo, el querido Presidente, Sr. Turell, ha tenido la bondad de encargarme a mi el dirigirles Ia palabra en nombre del consejo del Instituto en este simpático banquete de despedida.

Agradezco mucho este señalado honor, que me da ocasión de saludar a todos vosotros, empezando por esas bellas y distinguidas damas que han querido acompañarnos en este acto, rubricando, con la fuerza que tiene siempre el testimonio de su compañia, el acusado sello de compenetración y amistad entre los técnicos del cemento que han tenido los Coloquios que hoy terminan.

Decía esta tarde el llustre Delegado del Gobierno en la Industria del Cemento, D. José Vierna (a quien también hemos de agradecer el que asista a estos actos con su distinguida esposa), que le ha impresionado profundamente la sinceridad con que en las sesiones 
de los Coloquios se comentaban los interesantes asuntos planteados por los ponentes en tantos y tan variados temas como se han tratado en estos días, sin reserva alguna, intercambiando datos o resultados y expertencias que, en otras actividades, cada cual acostumbra a guardarse como un secreto profestonal.

Yo creo, señores, que precisamente la consecución de ese clima de conflanza y sinceridad mutuas en el intercamblo de ideas, fué el secreto del éxito de los I Coloquios, ha sido el de los II, y asegura la continuldad y la eflcacia de los mismos.

El Consejo del Instituto está plenamente satisfecho, en este sentido, del resultado alcanzado, y espera y confía en que cada día más, los fabricantes y los técnicos del cemento, considerando como cosa propia las instalaciones del Instituto, y contando con la eficacísima colaboración de los magnificos elementos técnicos que en ellas trabajan a diario, nos confien sus problemas para su estudio y posible solución, aportando su colaboración personal también, en los casos que Io requieran o deseen.

Estos problemas técnicos están tan intimamente relacionados con los económicos y aun con los comerciales y de distribución, que a mi juicio sería muy difícil separarlos.

Yo no comprendo--es decir, sí lo comprendo, porque sé que los periodistas decimos muchas tonterías-cómo a raiz de los I Coloquios, pudo alguien escribir que "más valía que los fabricantes, en lugar de hacer el sabio, se dedicaran a producir más cemento".

Pero yo pregunto: ¿es posible producir más cemento sin estudiar. los problemas de esa producción? ¿Es que los problemas técnicos y su resolución no implican el producir más y mejor?

Cuando estudiamos las dificultades de los forros refractarios o de los anillos, la mala calidad de los carbones, o el rendimiento de las grandes voladuras, pongo por caso, estamos solventando o pretendiendo solventar el probiema fundamental e intrínseco de la Industria: Ia continuidad de su funclonamiento durante las veinticuatro horas del dia y los

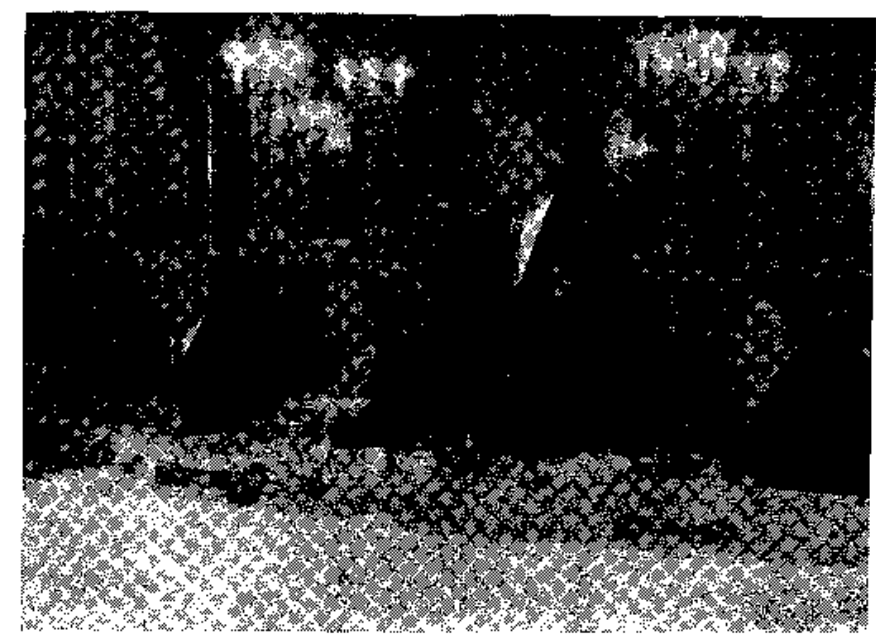

trescientos sesenta y cinco días del año, que son exactamente las horas y los días que los directores y técnicos de las fábricas de cemento dedican a su tarea.

Sin desfallecimientos, aun sabiendo que muchas veces no ha de venir compensada con la satisfacción de ver premiados sus desvelos con una cifra de producción que debiera corresponder, a su entusiasmo.

$Y$ no quiero extenderme demasiado, pero quisiera aprovechar la ocastón de corresponder a las amabllísimas frases, y aun piropos, que nos ha dedicado esta tarde el excelentísimo sefior Delegado del Gobierno, para agradecérselo en nombre de todos los aqui asistentes, diciéndole, además, que tenga la absoluta certeza de que, al igual que a sus dignos antecesores, no ha de faltarle la colahoración de los técnicos del cemento en la ingente tarea que le ha encomendado el Gobierno del Caudillo.

Los fabricantes de cemento, auxiliados por sus técnicos, algunos de ellos durante ya más de medio siglo, han dedicado todos sus afanes, todos sus conocimientos, sus medios económicos y yo diria que todos esos pregonados grandes beneficlos, fundamentalmente a mejorar sus industrias, como bien claramente lo patenttza esa cifra de más de cuatro millones de toneladas producidas el último año, que duplica la alcanzada hace solamente un lus- 
tro, cosa tal vez no lograda en ninguna otra de las actividades nacionales.

$Y$ probablemente esa cifra seria intensamente mejorada, sin necesidad de contar con la que proporctonen las nuevas instalaciones, si se Iograra resolver y garantizar el angustioso problema del suministro de combustible $\rightarrow y$ no digo carbón, pues ya juega también el fuel-oil-, $y$ el de las disponibilidades de divisas, dadas las cantidades relativamente modestas, precisas para ciertas instalaciones complementarias de las existentes, que permitirian el logro de la productividad necesaria, que, sin querer equipararla a la americana, ha sido ya cifrada con metas fácilmente alcanzables, en una de las ponencias discutida esta misma mañana.

En las sesiones, creo que esa ponencia, como todas las demás sometidas a la consideración de los concurrentes a los Coloquios, ha sido prueba evidente de que en el Instituto no se hace clencia pura, sino clencia aplicada $y$, por tanto, tarea tangible y eflcaz, con el solo anhelo de colaborar al mejor desarrollo de la Industria del Cemento $\mathrm{y}$, por consiguiente, de elevar el nivel de la economía de la Patria.

Y nada más, sino agradecer a todos su colaboración y eficaz labor durante los agradables días transcurridos en el seno del Instituto; a los jóvenes premiados, mi felicitación y mi estímulo para que prosigan en su brillante actuación, en la que tanto confiamos los que ya empezamos a sentir la fatiga deI trabajo. $\mathrm{Y}$ a todos la más cariñosa despedida en nombre del Consejo y en el mío propio, diciéndoles, de todo corazón, gracias y hasta pronto si Dios quiere."

A continuación, el Ingentero Industrial don Sebastián Carpi, Consejero-Delegado de Cementos Turia, S. A., recogtendo el sentir de todos los directores y técnfos asistentes a los II Coloquios, se expresó así:

"Excelentísimos e llustrísimos señores; senoras; companteros y amigos:

Como técnico y como fabricante, tengo que declr unas palabras para declarar, con la ambición de interpretar a todos los que hemos concurricio a estos Ir Coloquios de Directores y Técnlcos de Fábricas de Cemento, el efusivo y sincero sentimiento de gratitud que debemos al Consejo Técnico Administrativo del Instituto Técnico de la Construcción y del Cemento, que ha sabido organizarlos con tanta exquisitez de espiritu y tan alta escuela, habiéndonos permitido tratar temas serlos y prácticos, conviviendo como estudiantes en un clima amable, muy difícil, aunque no imposible de alcanzar, porque se ha logrado plenamente, entre antagonistas en el terreno económico de la competencia. La bandera de la Técnica, sostenida con gran amor a nuestra disciplina, ha tenido la virtud de fundirnos en hermandad de trabajo eficaz por su desinterés, y por la pasión que ese equipo magníflco de secretarios, $\mathrm{y}$ en suma, de todos los colaboradores femeninos y masculinos de esta Institución, han sabido contagiarnos.

Volvemos a nuestras fábricas sabiendo algunas cosas más de orden concreto, porque los ponentes y actores, compatriotas y extranjeros, de los Coloquios, nos han comunicado, con esa sencilla naturalidad que confiere la

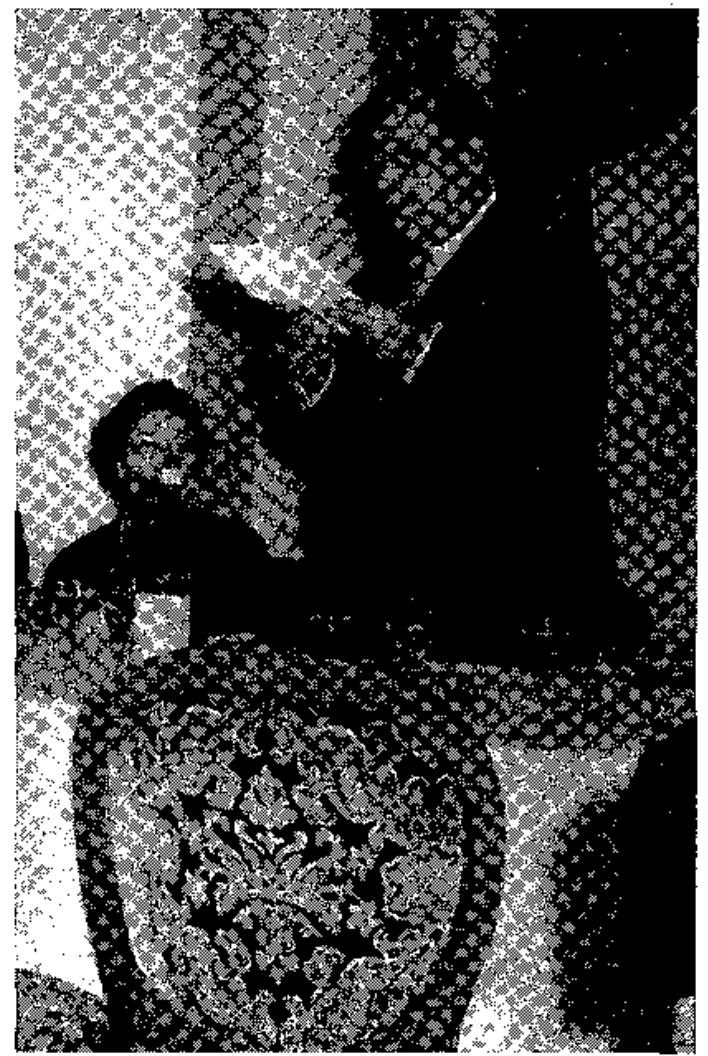


altura de llamarse Rezola, Lumbier, Palomar, Gascuñana, lo que cada cual sabía como fruto de sus esfuerzos, desvelos y preocupaciones. Gracias también para vosotros.

Nos vamos contentos y confiados a nuestras casas, porque también sabemos que aquí queda nuestro hogar técnico, donde cualquier problema que pueda surgix en nuestra vida industrial encontrará solícita acogida, solución concreta y trato caballeresco. Os habla quien ya tiene experiencia por haber necesitado del concurso siempre útil y muy interesante de nuestro Instituto para elevar el nivel de la técnica $\mathrm{y}$, por tanto, de la fabricación de los cementos españoles; contribución esforzada que tantos beneflcios reporta para el desarrollo de las fuentes de riqueza de España, hecha desde este observatorio con instrumentos valiosísimos e instalaciones maravillosas, pero, sobre todo, y superando el valor y la maravilla de las cosas materiales, por el personal que forma el cuerpo de esta organización, llena de un alma generosa que satura de grandeza esta actividad española.

Os descubro el secreto a los que no lo sabíais: ésta es como nuestra casa madre, a la que si pedís orientación, consejo y ayuda, slempre os lo proporcionará.

La feliz coincidencia del reciente nombramiento del Coronel Vlerna, flbra de héroes, para el importante cargo de Delegado del Gobierno en la Industria del Cemento, y su pa- triótica inquietud por la misión que le ha sido conflada, ha permitido que estos II Coloquios tuvieran también la virtud de acercarnos recíprocamente. Gracias tambtén al \$r. Vierna por haber querido vivir con nosotros nuestros problemas técnicos, pues así conocerá directamente $\mathrm{y}$, por lo tanto, mejor, cuántas inquietudes comporta un simple saco de este material básico que este grupo de hombres, de trabajo y de ciencia, produce para el progreso de España. Y contemplando nuestras actividades, recuerde aquel cuadro del genial sorolla que representa los quehaceres, los afanes y las zozobras de los pescadores que buscan en el mar su sustento, y cuyo título reza: “ $\mathrm{j} Y$ aún dicen que el pescado es caro!"

En esta ocasión queremos dedicar un emocionado recuerdo al que fué primer Delegado, D. Félix González, Coronel đe Ingenieros, y al que ocupó el cargo después, D. Domingo Gonzólez Regueral, ilustre Ingeniero de Minas, quienes llenaron su cometido digna y eficazmente.

Pero todo esto no hublera sido posible, a pesar de toda la inteligencla y buena voluntad demostradas, si Dios no hubiera querido darnos a esta generación la inmensa suerte de vivir en orden y en paz, con todos los defectos humanos que queráis, pero como no se vive en ninguna parte del mundo, gracias al Generalísimo Franco, a quien ofrecemos, con nuestro reconocimíento, nuestro respeto $\mathrm{y}$ adhesión."

J. C. C 